that injections of histamine produce a similar condition; it annuls the "tone" of the capillary vessels, so that they dilate and their walls become abnormally permeable. In cases of considerable injury to muscles (one of the most potent causes of shock) a substance like histamine is generated. Histamine acts more powerfully in animals anæsthetised with ether, and surgeons during the war have noted that patients suffering from shock bear ether badly.

In the Section of Preventive Medicine the dysenteries were considered. Col. Leonard Dudgeon discussed the bacillary form. The dysentery bacillus is scarcely ever present in the blood-in only two cases out of 145 cases examined. The methods of bacteriological examination for the dysentery bacilli were described, and the three methods by which the disease may be spread among a healthy population referred to. These are by "carriers," by infection of water, and by flies. As regards flies, typical dysentery bacilli were isolated from wild flies captured and examined.

Amœbic dysentery was dealt with by Dr. Warrington Yorke. The dysentery amœba is apparently indigenous in England, for it had been found that of 450 civilians in the Liverpool Royal Infirmary who had never been abroad, $I \cdot 5$ per cent. were infected. Among recruits $5 \cdot 6$, and among lunatics $9 \cdot 7$, per cent. were found to be infected.

Lt.-Col. Dale Logan gave a demonstration on minegas poisoning. $\mathrm{Bv}$ the autumn of I9I5 mine warfare had made huge strides, and, with the great increase in size of the explosive charges used, more extensive mine systems, and the employment of thousands of men underground, the casualties from mine-gas poisoning assumed serious proportions. The poisoning was entirely due to carbon monoxide gas. The insidious nature of the poisoning and the serious nature of the casualties lent support to rumours that the enemy was employing a new gas and forcing it through into our galleries. The intensity of mine warfare might be gauged by the fact that in I9I6 we fired 750 , and the enemy 700 , mines. At Messines some mines were charged with $90,000 \mathrm{lb}$. of explosive, and the total charges in all the mines totalled more than $1,000,000 \mathrm{lb}$. A description was given of the organisation to cope with mine-gas poisoning and of rescue apparatus emploved.

Other important discussions and demonstrations were on malaria, injuries of blood-vessels, gunshot wounds of the chest. and bone inflammation and bone repair. details of whirh will be found in the issues of the British Medical Journal.

\section{AGRICULTURAL RESEARCH IN MADRAS.}

$T H E$ rgis Year-book of the Madras Agricultural Department ${ }^{1}$ indicates that the officers of the department are giving attention to a variety of problems of great local importance. No results of wide significance for tropical agriculture are recorded, but a good deal of useful work has been done, which is not without its value bcyond the Indian province in which it was carried out.

In "A Note on Grading Cotton" Mr. R. C. Wood gives the results of a grading trial made with cotton grown at the Coimbatore Agricultural College. The crude cotton and the two grades produced in the trial were submitted for valuation to five firms-three spinners and two buyers for export. If rooo $\mathrm{lb}$. of lint had been graded and sold to each of two of the firms on the basis of these valuations; the reduction in profits as the result of grading would have been 32 and 6 rupees respectively, whilst a similar operation with the three remaining firms would only have added 4,4 , and 77 rupees respectively to the price realised for

3 (Madras: Superintendent, Government Press, rgr8.) Price $x s .9 d$. NO. $258 \mathrm{I}$, VOL. IO3] a like quantity of ungraded cotton. More interest is now being taken in Indian cotton in Great Britain, and the utility of this note to the British reader would have been much enhanced if results of examination of the crude and graded cottons had been given in detail as well as the valuations. In explanation of the disappointing results, the author is only able to suggest that possibly the crop was of poor quality owing to the bad season, and that consequently there was less difference between the crude cotton and the first grade than would normally be the case.

Mr. T. V. R. Ayyar writes on the habits and lifehistory of Pempheres affinis, Faust, a stem weevil, which attacks Cambodia cotton. Treatment of the stems with the usual insecticides has not so far protected the crops from serious damage, but the removal and destruction of the plants first attacked in a plantation have sufficed to check the spread of the pest, and the author suggests that the practice adopted in Uganda of clearing and destroying all cotton plants, after the crop is harvested each year, would probably be a useful preventive measure.

Dr. Harrison, Government Agricultural Chemist, contributes "A Report upon the Extent and Character of the Saline Lands of the Madras Presidency" and "Some Notes on Manures in Southern India." The latter refers to the available sources of supply of lime, gypsum, magnesia, and phosphates, and gives information as to the poonacs (oil-cakes) and fish manures obtainable in the Presidency. A paper by $\mathrm{Mr}$. M. R. R. Sivan on "Phosphatic Nodules of Trichinopoly and their Availability as Manure" is also of interest in this connection. It appears that since $I 892$ much correspondence and several negotiations regarding concessions to work this area for phosphates have taken place, but so far only small quantities have been extracted for local use.

Dr. F. Marsden has a note in the Year-book on "A Hot-water Process for the Extraction of Indigo," but this subject and other matters relating to indigo are more fully dealt with in the same author's "Indigo Manufacture in Madras," which forms No. 74 of the Madras Department of Agriculture Series of Bulletins. $^{2}$ Before starting on his tour of inspection of the Madras indigo districts the author had the advantage of visiting with Mr. W. A. Davis, Indigo Research Chemist to the Government of India, some of the chief Indian indigo factories managed by Europeans, and chiefiy situated in Behar. In Madras indigo cultivation and manufacture are almost entirely in the hands of natives, though in at least one instance a European firm issues seed to the ryots and provides vats in which the crop can be worked up for dyestuff; a similar arrangement is sometimes adopted on a smaller scale by native merchants. In most cases, however, the ryot sells his crop to a native vat-owner, or hires a vat in which to manufacture the dyestuff. No records are kept as to yields, and Dr. Marsden regards as untrustworthy the rough estimates he was able to get, which are much higher than the yields recorded in Behar. Though indigo as rich in indigotin as that produced in Behar is made in Madras, the quality is, on the whole, poor, and, what is perhaps worse, variable. These defects are due chiefly to carelessness in manufacture, but also in part, at any rate in some areas, to deliberate adulteration with clav and mud.

The work already done by Mr. Davis in India has shown that the cultivation and manufacture of indigo. even in Behar, where the industry is in the control of Europeans and comparatively well organiser, presents many problems, which, if solved. might greatly improve its position and prospects. In the case of

2 (Madras : Superintendent, Government Press, 1918.) Price $6 d$. 
the native industry. carried on in Madras, Dr. Marsden points out that the difficulties are much more formidable, and he suggests that the first step towards improvement must be the provision of means for the production of indigo of good and uniform quality. One means to this end would be the replacement of small-scale manufacture in nativeowned vats by larger-scale production in well-managed factories, the ryot selling his crop to the factory for manufacture into dyestuff. A possible alternative may be the elaboration of a simple process, capable of being used by the ryot, as the result of the researches now being carried on by $\mathrm{Mr}$. Davis, coupled with some system of analytical control of the produce before shipment.

\section{USES OF INVISIBLE LIGHT IN WARFARE.}

YROF. R. W. WOOD, of Johns Hoplins University, Baltimore, gave to the Physical Society of London on March is a demonstration of the uses of invisible light in warfare. The first device shown was a signalling-lamp, consisting of a 6-volt electric lamp with a small curled-up filament at the focus of a lens of about 3 in. diameter and 12 in. focus. This gave a very narrow beam, only visible in the neighbourhood of the observation post to which the signals were directed. In order to direct the beam in the proper direction, an eyepiece was provided behind the filainent. The instrument was thus converted into a telescope, of which the filament served as graticule. When directed so that the image of the observation post was covered by the filament, the lamp, when lit, threw a beam in the proper direction. In many circumstances the narrowness of the beam was sufficient to ensure secrecy; but sometimes it was not desirable to show any light whatever, and filters were employed to cut out the visible spectrum. By day a deep red filter, transmitting only the extreme red rays, was placed. in front of the lamp. The light was invisible to an observer unless he was provided with a similar red screen to cut out the daylight, in which case he could see enough to read signals at six miles. By night a screen was used which transmitted only the ultra-violet rays. The observing telescope was provided with a fluorescent screen in its focal plane. The range with this was also about six miles. For naval convoy work lamps are required which radiate in all directions. Invisible lamps for this purpose were also designed. In these the radiator was a vertical Cooper-Hewitt mercury arc, surrounded by a chimney of the ultra-violet glass. This glass only transmits one of the mercury lines, viz. $\lambda=3660 \AA$.U., which is quite beyond the visible spectrum. Nevertheless, the lamp is visible at close quarters, appearing of a violet colour, due to fluorescence of the retina. The lens of the eye is also fluorescent. This gives rise to an apparent haze, known as the "lavender fog." which appears to fill the whole field of view. Natural teeth also fluoresce quite brilliantly, but false teeth appear black.

Reverting to the use of the lamps at sea, they are picked up by means of a receiver consisting of a condensing lens in the focal plane of which is a barium-platino-cyanide screen the full diameter of the tube. An eyepiece is mounted on a metal strip across the end of the tube. When the fluorescent spot has once been found somewhere on the screen, it is readily brought to the central part and observed with the evepiece The range is about four miles, and the arrangement has proved invaluable for keeping the shins of a convoy together in their proper relative positions by night.

NO. $258 \mathrm{I}$, VOL. I03]

\section{UNIVERSITY AND EDUCATIONAL} INTELLIGENCE.

LONDON.-A course of eight lectures on "The Physiology of Muscular Exercise" will be given in the Physiological Department, St. Bartholomew's Hospital Medical School, West Smithfield, E.C.I, by Prof. F. A. Bainbridge on Wednesdays at 4.30 p.m., beginning on April 30 . The course is intended for advanced students of the University and others interested in the subject. Admission is free, without ticket.

WE learn from Science that by the will of the late Mr. Morton F. Plant the Connecticut College for Women receives a bequest of $50,000 l$.

Sir Arthur Newsholme has been offered the chair of public health at Johns Hopkins University, Baltimore, and it is understood that he will accept the offer for a year at least.

THE sixth election to Beit fellowships for scientific research will take piace on or about July ${ }^{1} 5$. Not more than three fellowships, of the value of $175 l$. per annum, will be awarded. Applications must be received on or before May $3^{\mathrm{r}}$. Forms of application and all information may be obtained, by letter only, addressed to the Rector, Imperial College, South Kensington, London S.W.7.

By the will of the late Mr. Charles Kerr Marr, the residue of his propertv, amounting apparently to more than $200,000 l$., is left in trust for educational purposes, defined as follows :- " For granting prizes or rewards to persons who are or have been bona-fide residents in the borough of Troon, and who are or have been scholars in some public or elementary school: in or towards building or maintenance of any public school, elementary or otherwise, in Troon; in or towarás the maintenance of exhibitions or scholarships tenable at any institution of education hioher than elementary, as the trustees mav determine. but no exhibition or scholarship shall be awarded to anv person who shall not be or have been a bona-fide resident in Troon."

In the issue for April 5 of the Cologne Post, a daily paper published at Cologne by the Army of the Rhine, is an article on the education of $\mathrm{A}$ iv, boys. The writer states that the boys of eighteen years of age who have been called to the colours recently have, in the majority of cases, proved to be vastly below the standard of education to be expected of boys of that age, as many as 5 per cent. of them being quite illiterate. He goes on to advocate the institution of a system of vocational education while the boys are with the Army of Occupation that will return these lads to their civil occupations each one with his studies completed and with his "apprenticeship" served. The curriculum and time-table of studies sketched in the article indicate a due appreciation of the difficulties of the problem and the possibility of overcoming them successfully.

The Cologne Post of April I publishes an interesting account of the work of the 2 nd Army Agricultural College at Bonn. The object of the college is to provide interesting and useful occupation for our troops during the period preceding demobilisation. Courses were commenced in January, I919, since which time large numbers of soldiers, both officers and other ranks, have received short courses of agricultural instruction. At first the lectures were mainlv theoretical, dealing with agricultural chemistry and botanv, but this was soon altered. and at the present time the students not only have lectures on practical subjects-farm management, etc.--but are also 